\title{
O PAPEL DA LIDERANÇA NO EMPREENDEDORISMO
}

Jerson Joaquim da Silva, Daniel Melanda Signorini

Faculdades de Tecnologia do Estado de São Paulo - FATEC, Presidente Prudente, SP. E-mail: jersonjsilva@hotmail.com; daniel_alt22@hotmail.com.

\section{RESUMO}

Esse artigo abordou o papel da liderança no empreendedorismo. Para a melhor compreensão do tema discorreu-se sobre liderança e empreendedorismo, procurando mostrar a interface entre estes dois temas. A pesquisa teve como objetivos: analisar o papel da liderança no desenvolvimento do empreendedorismo, identificando de que maneira o mercado de trabalho favorece o líder na fomentação do empreendedorismo, apontando as dificuldades que um líder tem em se tornar um empreendedor e determinando quais aspectos necessários para que um líder se torne empreendedor. Foi utilizado como metodologia, uma abordagem qualitativa por se tratar de uma pesquisa bibliográfica, utilizando-se livros, sites, artigos e dissertações que trataram dos assuntos pesquisados, que ao longo do tempo mudam, tendo como características as mais variadas ideias. A pesquisa mostrou que para um líder ser empreendedor, primeiramente, deve-se ter confiança naquilo que está realizando, ver uma oportunidade e usála; pensar sempre na inovação de seu produto ou serviço.

Palavras-Chaves: Empreendedorismo; Liderança; Mercado de Trabalho.

\section{THE LEADERSHIP ROLE IN ENTREPRENEURSHIP}

\begin{abstract}
This article broached the role of leadership in entrepreneurship. For a better understanding of the theme, leadership and entrepreneurship were explained, seeking to show the relation between these two themes. The research had aimed on to analyze the role of leadership in the development of entrepreneurship, identifying how the job market favors the leader in fomenting entrepreneurship, pointing out the difficulties a leader has to become an entrepreneur and determining which aspects are necessary for a leader to do so. A qualitative approach was used as methodology because is a bibliographic research making use of books, sites, articles and essays that comprehend the research's objective, where the most varied ideas were included, considering that some of them may change over time. The research showed that for a leader to become an entrepreneur, firstly confidence in actions is needed, once an opportunity appears he must take it and should always think in innovation for his product or service.
\end{abstract}

Keywords: Entrepreneurship; Leadership; Job market. 


\section{INTRODUÇÃO}

Ao discorrer sobre o assunto liderança e empreendedorismo uma coisa torna-se inquietante: o fato de que o empreendedor, antes de tudo, deve ser um sonhador. Esta palavra fica impregnada no imaginário do pesquisador, pois acredita-se que seja a mola propulsora de quem deseja empreender seu próprio negócio.

É importante salientar que antes de ser um empreendedor na área dos negócios, a pessoa deve empreender em sua mente os desafios que enfrentará e as ferramentas que usará para atingir os objetivos, a fim de nortear o foco desejado.

Supõe-se que sair da zona de conforto requer iniciativa e persistência por parte de todos, enfrentar o novo e o incerto, por outro lado requer determinação, com o intuito de que se tenha uma nova forma de gestão, um novo modelo de liderança e uma perspectiva de mudança, ou seja, uma nova cultura.

Nesse sentido, esta pesquisa se justifica, pois aborda-se o papel da liderança no empreendedorismo. E para a melhor compreensão do tema proposto, discorreu-se sobre liderança e empreendedorismo, procurando mostrar a interface entre estes dois temas.

Pontua-se que liderança consiste em pessoas que têm como característica principal ser líder, ou seja, têm maior facilidade em desenvolver a capacidade para enxergar a organização e as outras pessoas com outros olhos, tendo importância em todo meio da sociedade e nas organizações, sendo elas: escolas, trabalhos, organizações públicas, meios religiosos e políticos, entre outros.

Por outro lado, o empreendedorismo está relacionado com a origem de novas empresas ou elaboração de novos produtos. Dessa forma, um empreendedor tem que conciliar princípios, detectando novas oportunidades e transformando-as em negócios lucrativos. Sendo importante para a concepção de riquezas dentro de um país, favorecendo o crescimento econômico e melhorando as condições de vida da população, além de ser um fator considerável na geração de novos empregos e renda.

Para nortear esta pesquisa, pontuaram-se os seguintes objetivos: como objetivo geral: analisar o papel da liderança no desenvolvimento do empreendedorismo e como objetivos específicos: identificar de que maneira o mercado de trabalho favorece o líder a fomentar o empreendedorismo; apontar as dificuldades que um líder tem em se tornar um empreendedor e determinar quais aspectos serão necessários para que um líder se torne empreendedor.

\section{METODOLOGIA}

Como metodologia, este trabalho teve uma abordagem qualitativa por se tratar de uma pesquisa bibliográfica. Fez-se uso de livros, sites, artigos e dissertações que trataram dos assuntos pesquisados. Por se tratar de uma pesquisa bibliográfica, a mesma teve seu início com o desenrolar do projeto e foi concluída em abril de 2018.

\section{DISCUSSÃO}

Nota-se que com o passar do tempo, ocorrem mudanças em tudo, ou seja, os problemas, inovações, pessoas, meio ambiente, tudo se transforma, somente a liderança que persiste e continua o mesmo conceito, com as características de ações intactas, pois líderes empreendedores são aquelas pessoas que têm iniciativa, criatividade, assume riscos, são persistentes e que tomam decisões à frente dos demais, ou seja, líder empreendedor é aquele que aproveita as oportunidades para criar algo novo e transformá-lo em um sucesso pessoal e profissional tendo maiores responsabilidades. 
Contudo, pode-se afirmar que através dos empreendedores surgiram novas ideias, novas criações, novas empresas, novas formas de gerenciamento, arriscando constantemente, desviando os recursos existentes para deslocar-se da monotonia de uma ordem estabelecida. Assim faz com quem esteja ao redor dessas obras se estabilize e caminhe de acordo com os passos do empreendimento, ou seja, os empreendedores são "eternos revolucionários", que criam obras com "tijolos de ouro".

Segundo Ulrich, Smallwood e Sweetman (2015, p. 19) "Os líderes que conseguem controlar um equilíbrio entre os resultados dos empregados, dos clientes, dos investidores e da organização como um todo terão maior probabilidade de vencer".

Os líderes, além de ter um equilíbrio em todos os processos, devem saber qual o resultado esperado por eles e por toda a organização, pois só assim seguirão os planejamentos para atingir o sucesso.

Segundo Bergamini (2006, p. 130) "[...] o líder eficaz deixa claro o caminho a ser tomado, para facilitar que seus seguidores possam atingir a realização dos próprios objetivos." Um líder empreendedor mostra-se carismático, paciente, gentil, disciplinado e acima de tudo, capaz de influenciar seus colaboradores, motivando-os para que juntos trabalhem em equipe, atingindo dessa forma os objetivos traçados pela organização.

Segundo Bennis (1995, p. 58) Líderes eficazes fazem vistas grossas aos erros e constantemente adotam metas positivas. Concentram suas energias na tarefa a ser desempenhada, sem olhar para trás ou vasculhar o passado. Os líderes eficazes além das características citadas pelo autor, devem ser comprometidos, terem uma perspectiva ampla de todos os acontecimentos e mudanças e inspirarem confiança a seus liderados.

Segundo Botelho (1991, p. 85):

É possível formar, treinar e desenvolver gerentes competentes. Mas formar líderes é mais difícil. Na formação do líder, o ambiente e a situação tem, muitas vezes, mais importância do que o treinamento específico. Não adianta apenas o aculturamento sobre liderança para que tenhamos um "produto acabado", há necessidade que o ambiente e as necessidades circunstanciais facilitem o surgimento e a atuação do líder.

Líderes são diferentes de gerentes, pois os gerentes focam nos processos em busca somente de resultados e lucros, já os líderes visam treinar e qualificar seus colaboradores, proporcionando conhecimentos elevados, para assim, gerar lucratividade e desenvolvimento da empresa, pois tendo pessoas com qualidade de serviço e empenho serão motivadas e procurarão crescer juntamente com a empresa.

Segundo o autor Botelho (1991, p. 31):

O gerente apóia-se nas regras, normas e procedimentos, enquanto o líder se apóia nas pessoas, suas capacitações e habilidades. Para o gerente a rotina diária é uma batalha constante a ser vencida; enquanto para o líder ela é o reinício de novas oportunidades. Para o gerente as crises são problemas desgastantes e aborrecidos; para o líder são situações inevitáveis que têm de ser enfrentadas com competência e discernimento (oportunidades).

Como o autor afirma, líder que é líder tem uma visão maior do que gerente, pois o foco dos gestores é seguir os procedimentos, já os líderes, se preocupam com as pessoas, suas capacidades e habilidades de proporcionar à empresa mais resultados.

Segundo o autor Sertek (2012, p. 107):

[...] é necessário que estejamos atentos a um falso conceito: o de que líder nasce líder. Isso não é verdadeiro. As empresas precisam investir em capacitação, em profissionais 
para formar profissionais e que os capacitadores sejam hábeis na tarefa de formar, de conduzir as pessoas a estágios mais avançados de competências.

Para ser um líder empreendedor é importante que o líder se capacite a ter as características necessárias para tal, que é ser íntegro, priorizar as pessoas e não somente os resultados, o líder precisa ser determinado, disciplinado, ter ética e saber se relacionar bem com as pessoas, sendo ou não seus colaboradores.

Segundo Bennis (1996, p. 51):

Se um dos ingredientes básicos da liderança é a paixão pelas perspectivas que a vida pode oferecer, a chave para realizar estas perspectivas é o empenho total, como fez Kaplan ao entrar para a Disney. Empenho total é simplesmente outra maneira de definir aprendizado.

Como já citado acima, sendo liderança a capacidade de influenciar as pessoas, numa determinada situação para se chegar ao objetivo planejado, é aconselhável que os líderes tenham empenho total no que vão desenvolver para incentivar os mesmos a seguir a meta planejada; líderes devem ser vistos como, modelos pelos seus liderados e não somente como gestores.

Para tornar-se um bom líder, primeiramente é preciso se conhecer, devendo sempre buscar maiores conhecimentos e estar atualizado com as novidades do mercado, a fim de passar aos colaboradores transparência, tranquilidade, respeito e confiança.

Segundo a autora Bergamini (2006, p. 94):

Não existe um perfil ideal de estilos, isto é, um comportamento que responda pela eficácia irrestrita dos líderes, ou seja, que os torne infalíveis. É necessário pensar que, antes de serem líderes, eles são apenas humanos. O autoconhecimento do próprio estilo parece ser a primeira condição, o primeiro passo rumo à eficácia futura.

Toda pessoa, indiferente de ser um líder, empreendedor, criativo, todos devem se valorizar acima de tudo, pois o ser humano que não está bem consigo, não consegue demonstrar competência e passar aos demais a serenidade exigida.

Segundo Ulrich, Smallwood e Sweetman (2015, p. 29) "Os líderes são aprendizes: aprendem com o sucesso, fracasso, as tarefas, os livros, as lições, as pessoas e a vida em si." Não somente os líderes, mas todas as pessoas em todo o ciclo de vida adquirem conhecimentos de alguma forma, mas algumas pessoas buscam com afinco estes conhecimentos, pois querem e têm um objetivo na vida, serem mais do que são, serem respeitadas e valorizadas pelos demais. Há os conhecimentos que aprendemos de acordo com a convivência com a família, cultura e religião, e há os conhecimentos que adquirimos pela leitura, pelos estudos e pela busca através de profissionais.

Segundo Maximiano (2007, p.51):

Para preparar um plano estratégico: (1) Defina sua missão e entenda sua situação estratégica (onde estamos?). (2) Analise o mercado da empresa para identificar as ameaças e oportunidades. (3) Faça o diagnóstico da empresa para avaliar seu desempenho e encontrar seus pontos fortes e fracos, com os quais você pretende enfrentar as ameaças e aproveitar as oportunidades. (4) Defina suas estratégias (para onde devemos ir?). 


\section{RESULTADOS}

A pesquisa apontou que o líder necessita ter em mente desde o primeiro processo do planejamento até onde se pretende chegar, de acordo com as etapas concluídas que ele irá verificar se foi idealizado e se o negócio é viável ou não; como o autor descreve, é necessária a definição da missão da empresa, ou seja, qual é o objetivo da existência da mesma, é preciso também analisar o mercado, somente deste modo a empresa irá ter maiores conhecimentos das suas desvantagens perante a concorrência e quais as oportunidades que poderão ser aproveitadas. O diagnóstico é um fator importante, porque serão identificados os pontos fortes e os fracos que já existem dentro da organização, e por fim, as estratégias, que é a meta, o objetivo que a empresa quer alcançar.

Segundo Posner e Kouzesm (2013, p. 293):

Nunca conhecemos um líder que não fosse nato. Assim como jamais deparamos com um contador, um artista, um atleta, um engenheiro, um advogado, um médico ou um zoológico que não fosse nato ou nado isto é, que ainda não tivesse nascido. A diferença está no que se faz com o que se é ou com o que se tem antes de morrer.

Supõe-se que para se tornar um bom líder é preciso saber quem realmente é, quais seus valores básicos e qual seu planejamento à longo prazo. Saber quais as características principais que lhe pertence, ajuda a perceber quem realmente é e onde se pretende chegar, ou com qual ramo de negócio se identifica.

Para um líder ser empreendedor, primeiramente, deve-se ter confiança naquilo que está realizando, não ter medo de errar, ver uma oportunidade e usá-la; pensar sempre na inovação de seu produto ou serviço.

Os líderes devem desenvolver várias habilidades para se obter sucesso, observa-se que para se tornar um líder empreendedor é necessário aproveitar as oportunidades em criar algo novo e transformá-lo em sucesso tanto pessoal, quanto profissional.

Para ser reconhecido como líder, é necessário saber como influenciar seus colaboradores a desenvolver suas respectivas tarefas, encarar sua vida como uma missão e não como uma carreira. O líder vai estimular o empreendedorismo a partir do momento que ele pensar à frente de seus concorrentes, ou seja, um líder torna-se um empreendedor quando ele vê uma ideia, planeja-a, e executa-a. Visando seu público alvo, favorecendo o crescimento econômico e gerando novas oportunidades de emprego.

Portanto, para a liderança tornar-se eficaz deve ser aquela, que consiga maior poder de influência no grupo de forma positiva, inspirando a terem objetivos em comum.

O líder transmite confiança à equipe, que junto com a meta planejada em comum , terão resultado excelente, fazendo com que a empresa se torne competitiva no mercado, devido a qualidade e cooperação dos colaboradores.

\section{CONSIDERAÇÕES FINAIS}

Diante do que foi exposto, a pesquisa postulou que o papel da liderança no desenvolvimento do empreendedorismo está interligado com a maneira de se pensar sobre sua vida pessoal e o mundo ao seu redor, ou seja, antes de se tornar um líder empreendedor de seu próprio negócio, a pessoa precisa ser capaz de saber liderar e empreender os pequenos projetos de sua vida particular. Nesse sentido, pressupõe-se que o mesmo deve ter domínio e conhecimento sobre as esferas comportamentais, psicológicas e emocionais. Desse modo, observa-se que muitos indivíduos têm capacidade de ser o que seus objetivos apontarem; só 
irão depender do modo que ingressarão no mercado e como se capacitarão para exercer tal função.

Notou-se que existem pessoas que demonstram ter um espírito de liderança, já outras treinam e praticam a liderança, assim obtendo mais experiência. Para que isso aconteça, independente das estratégias utilizadas, o líder empreendedor necessita ter comprometimento, trabalhar em equipe, ética, resiliência, espírito inovador, empatia, visão ampla do negócio, determinação, disciplina, iniciativa e criatividade, como premissas básicas para empreenderem com eficácia.

Percebeu-se que a maior dificuldade que um líder tem em se tornar um empreendedor é o medo de errar, fracassar e perder o que possuiu. Para um empreendedor, são nos erros que estão as chances de acertar, pois assim, aprenderá a não cometer novamente os erros passados.

Mesmo sabendo que o líder empreendedor é uma ótima característica, o que mais se encontra nos ambientes de trabalho ou são pessoas que só tem a característica de líder ou somente são empreendedores, havendo uma possibildade de treinamento para os colaboradores desenvolver este outro lado. Percebe-se que quando há líder empreendedor, o mesmo apresenta uma visão de futuro, é autoconfiante e tem a capacidade de inovação e criatividade.

A lideranca e o perfil empreendedor são habilidades que quando trabalhadas em conjunto faz com que as organizações se desenvolvam de maneira diferenciada. Muitas organizaçoes perceberam tal transformação que começaram a procurar líderes com o perfil empreendedor, para assim, garantir o sucesso da organização como um todo. 


\section{REFERÊNCIAS}

BENNIS, W. G. A formação do líder. 1 ed. São Paulo: Atlas, 1996.

BERGAMINI, C. W. O líder eficaz. 1 ed. São Paulo: Atlas S. A, 2006.

BOTELHO, E. F. Do gerente ao líder: A evolução do profissional. 2 ed. São Paulo: Atlas, 1991.

DEGEN, R. J. 0 empreendedor: empreender como opção de carreira. 1 ed. São Paulo: Pearson Prentice Hall, 2009.

DORNELAS, J. C. A. Empreendedorismo: Transformando ideias em negócios. 3 ed. Rio de Janeiro: Elsevier, 2008.

MAXIMIANO, A. C. A. Administração para empreendedores: fundamentos da criação e da gestão de novos negócios. 1 ed. São Paulo: Pearson Prentice Hall, 2007.

NAKAGAWA, M. Empreendedorismo: elabore seu plano de negócio e faça a diferença!. 1 ed. Rio de Janeiro: Senac São Paulo, 2013.

SERTEK, P. Empreendedorismo. 1 ed. Curitiba: InterSaberes, 2012.

POSNER, B.; KOUZES, J. O desafio da liderança: como aperfeiçoar sua capacidade de liderar. 5 ed. Rio de Janeiro: Elsevier, 2013. 